\title{
Prevalence and characteristics of asthma-COPD overlap syndrome identified by a stepwise approach
}

This article was published in the following Dove Press journal:

International Journal of COPD

20 June 2017

Number of times this article has been viewed

\author{
Hiromasa Inoue' \\ Takahide Nagase ${ }^{2}$ \\ Satoshi Morita ${ }^{3}$ \\ Atsushi Yoshida ${ }^{4}$ \\ Tatsunori Jinnai ${ }^{4}$ \\ Masakazu Ichinose ${ }^{5}$ \\ 'Department of Pulmonary Medicine, \\ Graduate School of Medical \\ and Dental Sciences, Kagoshima \\ University, Kagoshima, ${ }^{2}$ Department \\ of Respiratory Medicine, Graduate \\ School of Medicine, The University \\ of Tokyo, Tokyo, ${ }^{3}$ Department \\ of Biomedical Statistics and \\ Bioinformatics, Kyoto University \\ Graduate School of Medicine, Kyoto, \\ ${ }^{4}$ Medical Department, AstraZeneca \\ K.K., Osaka, ${ }^{5}$ Department of \\ Respiratory Medicine, Tohoku \\ University Graduate School of \\ Medicine, Sendai, Japan
}

Background and objective: There is increasing recognition of asthma-COPD overlap syndrome (ACOS), which shares some features of both asthma and COPD; however, the prevalence and characteristics of ACOS are not well understood. The aim of this study was to investigate the prevalence of ACOS among patients with COPD and its characteristics using a stepwise approach as stated in the recent report of the Global Initiative for Asthma (GINA) and the Global Initiative for Chronic Obstructive Lung Disease (GOLD).

Methods: This multicenter, cross-sectional, observational study enrolled outpatients who were receiving medical treatment for COPD. Clinical data, including spirometry results, were retrieved from medical records. For symptom assessment, patients were asked to complete the Clinical COPD questionnaire and the modified British Medical Research Council questionnaire.

Results: Of the 1,008 patients analyzed, 167 (16.6\%) had syndromic features of ACOS. Of the total number of patients, 93 and $42(9.2 \%$ and $4.2 \%)$ also had a predefined clinical variability of $\geq 12 \% / \geq 200 \mathrm{~mL}$ and $\geq 12 \% / \geq 400 \mathrm{~mL}$ in forced expiratory volume in 1 second $\left(\mathrm{FEV}_{1}\right)$, respectively, and therefore were identified as having ACOS. Conversely, the number of patients who had either syndromic or spirometric feature of ACOS was $595(59.0 \%, \geq 12 \% / \geq 200 \mathrm{~mL}$ $\mathrm{FEV}_{1}$ clinical variability), and 328 patients $\left(32.5 \%, \geq 12 \% / \geq 400 \mathrm{~mL} \mathrm{FEV}_{1}\right.$ clinical variability) had both the features. Patients identified as having ACOS were of significantly younger age, had a shorter duration of COPD, lower number of pack-years, better lung function, milder dyspnea symptoms, and higher peripheral blood eosinophil values compared with patients with COPD alone. The rate of exacerbations in the previous year was not significantly different between the ACOS and COPD groups.

Conclusion: Using a stepwise approach, as stated in the GINA/GOLD report, the proportions of patients identified as having ACOS were found to be $9.2 \%$ and $4.2 \%$ (depending on the $\mathrm{FEV}_{1}$ variability cutoff used) among the 1,008 outpatients medically treated for COPD in a real-life clinical setting.

Keywords: obstructive lung diseases, airway hyperresponsiveness, respiratory function tests, differential diagnosis

\section{Introduction}

Asthma-COPD overlap syndrome (ACOS) has been recognized as a condition characterized by the coexistence of some clinical features of both asthma and COPD, with the disease severity and clinical course differing from those of other chronic airway diseases. ${ }^{1,2}$

The proportions of ACOS patients among COPD patients in real-life clinical settings have been estimated in several reports previously. ${ }^{3}$ However, the designs and 
sampling methods of these studies have varied, and the prevalence values have ranged from $12 \%$ to $55 \%$, mainly because of the difference between the definitions of ACOS followed in each study, including airflow reversibility, spirometry, and clinical diagnosis. ${ }^{3}$ Such discrepancies in the definition of ACOS have complicated our understanding of the epidemiology and clinical characteristics of this disease in terms of the symptoms, frequency and severity of exacerbations, and disease burden.

Although a consensus on the exact definition and the diagnostic criteria of ACOS remains elusive, the recent report of the Global Initiative for Asthma (GINA) and the Global Initiative for Chronic Obstructive Lung Disease (GOLD) has highlighted a stepwise approach for the diagnosis of ACOS. ${ }^{1}$ In the first step, patients with chronic respiratory diseases are identified based on a detailed medical history, physical examination, and other investigations. In the second step, the extent of overlap between the features of asthma and COPD is assessed using differential syndromic features of these diseases. This step helps to identify and distinguish patients with typical asthma and those with typical COPD. Subsequently, diagnoses are confirmed based on spirometric measures, including reversibility of airflow limitation. Postbronchodilator (BD) increase in forced expiratory volume in 1 second $\left(\mathrm{FEV}_{1}\right) \geq 12 \%$ and $\geq 200 \mathrm{~mL}$ from baseline is listed as a common feature in ACOS patients, particularly if

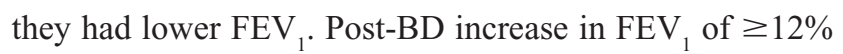
and $\geq 400 \mathrm{~mL}$ from baseline is also listed as a compatible factor for the diagnosis of ACOS.

This study aims to prospectively identify patients with ACOS using a stepwise approach, as stated in the GINA/ GOLD report, among outpatients receiving medical treatment for COPD. Patients were enrolled according to the protocol regulating consecutive recruitment to ensure the precise estimation of the proportion of ACOS patients in a real-life clinical setting. In addition, the clinical characteristics of ACOS patients were compared with those of patients with COPD alone.

\section{Methods}

\section{Study design}

This is a multicenter, cross-sectional, observational study of COPD patients treated by pulmonary specialists in Japan. Each center recruited outpatients according to the protocol regulating consecutive recruitment. Data on patients' characteristics, medical history, and laboratory measures, including spirometry results, peripheral blood eosinophil values, and fractional exhaled nitric oxide (FeNO) concentrations, were collected from medical records and were reported using an electronic case report form. After enrollment, patients were asked to complete two questionnaires for assessment of their symptoms, the Clinical COPD Questionnaire (CCQ) ${ }^{4}$ and the modified British Medical Research Council (mMRC) questionnaire for dyspnea, ${ }^{5}$ and to send these to the data center by mail.

This study was performed in accordance with the Declaration of Helsinki and the Ethical Guidelines for Medical and Health Research Involving Human Subjects established by the Japanese government. Written informed consent was obtained from eligible patients prior to any study-related procedures. The patients enrolled were free to withdraw at any time. The study was approved by the independent ethics committees of each participating center, coordinated centrally by the ethics review board of the Medical Corporation Toukeikai Kitamachi Clinic. This study was registered in ClinicalTrials.gov (identifier: NCT02413359).

\section{Patients}

Outpatients who were diagnosed with stable COPD by physicians, as defined in the GOLD guideline, ${ }^{5}$ were enrolled in this study. Patients were eligible for analysis if they fulfilled all of the following criteria: $\mathrm{FEV}_{1} /$ forced vital capacity (FVC) ratio $<0.7$ in past medical records, age $\geq 40$ years at the time of COPD diagnosis, current or ex-smoker with a history of $\geq 10$ pack-years, and availability of past ( $\geq 1$ year) medical records detailing COPD, including spirometry results. In addition, past airway reversibility test data or spirometry data measured at two different time points within the past 3 years, excluding those tested during COPD exacerbations, were required for eligibility.

Patients with a current COPD exacerbation episode or a history of lung cancer, or who were currently enrolled in any other interventional study or unable to understand the study procedure or to answer the questionnaires, were excluded.

For sample size determination, assuming that the proportion of patients with ACOS was 30\%, the smallest sample size needed to determine the proportion within $\pm 3 \%$ of the $95 \%$ confidence interval (CI) was 897 patients. Considering the potential number of patients with invalid data, we planned to enroll 1,100 patients in this study.

\section{Clinical assessments}

Syndromic features for diagnosing ACOS were defined based on the GINA/GOLD report, ${ }^{1}$ which included age at onset, pattern of respiratory symptoms, lung function, past or family history, time course, and chest X-ray (Table 1). An exacerbation was defined as any of the following events occurring within the past 1 year as a result of COPD worsening: change of 
Table I Features favoring asthma or COPD for syndromic diagnosis of airway disease based on the Global Initiative for Asthma/Global Initiative for Chronic Obstructive Lung Disease report

\begin{tabular}{|c|c|c|}
\hline Feature & Asthma & COPD \\
\hline Age of onset & Before age 20 years & After age 40 years \\
\hline Pattern of respiratory & Variation in symptoms over time & Persistence of symptoms despite treatment \\
\hline \multirow[t]{4}{*}{ symptoms } & Symptoms worsen during the night or early & Good and bad days but always daily \\
\hline & morning & respiratory symptoms and exertional dyspnea \\
\hline & Symptoms triggered by exercise, emotional change & Chronic cough and sputum preceded by \\
\hline & (including laughter), or exposure to dust/allergens & onset of dyspnea, unrelated to triggers \\
\hline Lung function & $\begin{array}{l}\text { Record of variable airflow limitation (spirometry, } \\
\text { peak flow) }\end{array}$ & $\begin{array}{l}\text { Record of persistent airflow limitation } \\
\text { (post-bronchodilator } \mathrm{FEV}_{1} / \mathrm{FVC}<0.7 \text { ) }\end{array}$ \\
\hline $\begin{array}{l}\text { Lung function } \\
\text { between symptoms }\end{array}$ & Normal & Abnormal \\
\hline \multirow[t]{2}{*}{$\begin{array}{l}\text { Past history or family } \\
\text { history }\end{array}$} & Previous doctor diagnosis of asthma & $\begin{array}{l}\text { Previous doctor diagnosis of COPD, chronic } \\
\text { bronchitis, or emphysema }\end{array}$ \\
\hline & $\begin{array}{l}\text { Family history of asthma and other allergic } \\
\text { conditions (allergic rhinitis, dermatitis) }\end{array}$ & $\begin{array}{l}\text { Heavy exposure to a risk factor: tobacco } \\
\text { smoke and biomass fuels }\end{array}$ \\
\hline \multirow[t]{3}{*}{ Time course } & $\begin{array}{l}\text { No worsening of symptoms over time. Symptoms } \\
\text { vary either seasonally or from year to year }\end{array}$ & $\begin{array}{l}\text { Symptoms slowly worsen over time } \\
\text { (progressive course over years) }\end{array}$ \\
\hline & May improve spontaneously or have a response to & Rapid-acting bronchodilator treatment \\
\hline & bronchodilator immediately or to ICS over weeks & provides only limited symptom relief \\
\hline Chest X-ray & Normal & Severe hyperinflation \\
\hline
\end{tabular}

Notes: Adapted with permission from Global Initiative for Asthma and Global Initiative for Chronic Obstructive Lung Disease. Diagnosis of diseases of chronic airflow limitation: asthma, COPD, and asthma-COPD overlap syndrome (ACOS).'

Abbreviations: $\mathrm{FEV}_{\text {, }}$, forced expiratory volume in I second; FVC, forced vital capacity; ICS, inhaled corticosteroid.

regular COPD treatment, administration of antibiotics and/ or systemic steroids, unscheduled/emergency room visit, or hospitalization. A moderate COPD exacerbation was defined as an exacerbation that required administration of an antibiotic and/or a systemic steroid but not hospitalization. A severe COPD exacerbation was defined as that requiring hospitalization. Symptoms and functional and mental states of patients were evaluated by the CCQ score. ${ }^{4}$ Dyspnea symptoms were evaluated by the mMRC scale. ${ }^{5}$

\section{Identification of patients with ACOS}

Patients with ACOS were identified using a stepwise approach as stated in the GINA/GOLD report. ${ }^{1}$ First, patients who had both three or more features favoring asthma and three or more features favoring COPD, as shown in Table 1, were selected as candidates for ACOS. In the next step, patients who also had variable airflow limitation were identified as having ACOS.

Variable airflow limitation was determined based on the results of airway reversible tests in medical records, as listed in the criteria of the GINA/GOLD report. ${ }^{1}$ In addition, we used long-term airway clinical variability (defined for this study as follows) as a criterion for ACOS. Patients who had

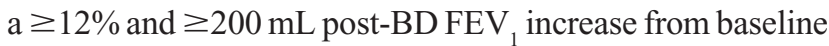
in the airway reversibility test and/or a difference of $\geq 12 \%$ and $\geq 200 \mathrm{~mL}$ between the highest and lowest $\mathrm{FEV}_{1}$ values in the past 3 years were identified as having ACOS with the $\geq 200 \mathrm{~mL}$ criterion. Alternatively, patients who had a $\geq 12 \%$ and $\geq 400 \mathrm{~mL}$ post-BD $\mathrm{FEV}_{1}$ increase and/or a difference of $\geq 12 \%$ and $\geq 400 \mathrm{~mL}$ between the highest and lowest $\mathrm{FEV}_{1}$ values in the past 3 years were identified as having ACOS with the $\geq 400 \mathrm{~mL}$ criterion.

The objective of the preplanned primary study was to identify the proportion of patients who had either syndromic features of ACOS or airway variability, or both. Proportions of patients identified as having ACOS by the stepwise approach were calculated by post hoc analysis. The GINA/GOLD report proposed the use of a stepwise approach to identify ACOS patients and to select treatments for untreated patients. However, the subjects of this study were patients who were diagnosed with COPD and were being followed by a physician. Hence, we initially established the preplanned definition to prevent the oversight of patients who may have complications associated with asthma. However, in recent studies of ACOS, ${ }^{6,7}$ it has become commonplace to identify patients with both symptoms and airway reversibility/variability to categorize them as having ACOS. Therefore, in this article, we decided to reevaluate and report our findings based on the identification of ACOS by the stepwise approach as proposed by the GINA/GOLD report, in order to more appropriately investigate the characteristics of ACOS patients.

\section{Statistical analysis}

Continuous variables were compared between patients with ACOS and COPD alone using the Student's $t$-test. The distributions of sex and smoking status were compared by Fisher's exact test, whereas the distribution of COPD 
stages was compared using the Wilcoxon rank sum test. All statistical analyses were performed using SAS version 9.3 (SAS International Inc., Cary, NC, USA).

\section{Results}

\section{Patient characteristics}

The study was conducted at 38 centers (hospitals/clinics) between 1 May and 31 July 2015. Consent for this study was obtained from 1,054 outpatients medically treated for COPD, and 1,008 eligible patients were included for analysis.
Patient demographics and characteristics are shown in Table 2. The majority of patients were male (93.0\%), the mean age was 73.5 years, and the mean duration of COPD was 69.0 months.

\section{Proportion of patients identified as having ACOS}

Patients with ACOS were identified by the stepwise approach (Figure 1). In the first step, 167 (16.6\%) of the 1,008 patients were identified as having syndromic features of ACOS (both three or more features favoring asthma and three or more

Table 2 Characteristics of patients with or without asthma-COPD overlap syndrome

\begin{tabular}{|c|c|c|c|c|c|c|c|}
\hline \multirow[t]{2}{*}{ Characteristics } & \multirow[t]{2}{*}{$\begin{array}{l}\text { Total } \\
(n=I, 008)\end{array}$} & \multicolumn{3}{|c|}{$\begin{array}{l}\text { ACOS defined by syndromic } \\
\text { features and FEV, variability } \geq 12 \% \\
\text { and } \geq 200 \mathrm{~mL}\end{array}$} & \multicolumn{3}{|c|}{$\begin{array}{l}\text { ACOS defined by syndromic } \\
\text { features and } F E V_{1} \\
\text { variability } \geq 12 \% \text { and } \geq 400 \mathrm{~mL}\end{array}$} \\
\hline & & $\begin{array}{l}\text { ACOS } \\
(n=93)\end{array}$ & $\begin{array}{l}\text { COPD alone } \\
(n=915)\end{array}$ & $P$-value & $\begin{array}{l}A C O S \\
(n=42)\end{array}$ & $\begin{array}{l}\text { COPD alone } \\
(n=966)\end{array}$ & $P$-value \\
\hline Sex (male) & $937(93.0)$ & $84(90.3)$ & $853(93.2)$ & $0.288^{*}$ & $38(90.5)$ & $899(93.1)$ & $0.53 I^{*}$ \\
\hline Age at enrollment (years) & $73.5 \pm 8.3$ & $69.2 \pm 9.8$ & $73.9 \pm 8.0$ & $<0.00 I^{\#}$ & $66.9 \pm 11.1$ & $73.8 \pm 8.0$ & $<0.00 \mathrm{I}^{\#}$ \\
\hline Height $(\mathrm{cm})$ & $163.0 \pm 6.9$ & $164.4 \pm 7.9$ & $162.9 \pm 6.8$ & $0.07 I^{\#}$ & $166.4 \pm 8.2$ & $162.9 \pm 6.8$ & $0.00 I^{\#}$ \\
\hline Weight (kg) & $59.4 \pm 10.9$ & $62.0 \pm 11.2$ & $59.1 \pm 10.8$ & $0.014^{\#}$ & $63.4 \pm 12.3$ & $59.2 \pm 10.8$ & $0.015^{\#}$ \\
\hline BMI $\left(k g / m^{2}\right)$ & $22.3 \pm 3.5$ & $22.8 \pm 3.4$ & $22.2 \pm 3.5$ & $0.092^{\#}$ & $22.8 \pm 3.7$ & $22.3 \pm 3.4$ & $0.329^{\#}$ \\
\hline COPD duration (months) & $69.0 \pm 51.4$ & $54.0 \pm 52.0$ & $70.5 \pm 51.1$ & $0.003^{\#}$ & $39.3 \pm 31.1$ & $70.3 \pm 51.7$ & $<0.00 \mathrm{I}^{\#}$ \\
\hline \multicolumn{8}{|l|}{ Smoking status } \\
\hline Current smoker & $146(14.5)$ & $14(15.1)$ & $132(14.4)$ & \multirow{2}{*}{$0.877^{*}$} & $8(19.0)$ & $138(14.3)$ & \multirow{2}{*}{$0.372 *$} \\
\hline Ex-smoker & $862(85.5)$ & 79 (84.9) & $783(85.6)$ & & $34(81.0)$ & $828(85.7)$ & \\
\hline Pack-years & $56.9 \pm 31.3$ & $46.0 \pm 27.7$ & $58.1 \pm 3 \mid .5$ & $<0.00 \mathrm{I}^{\#}$ & $40.6 \pm 21.9$ & $57.7 \pm 31.5$ & $<0.00 \mathrm{I}^{\#}$ \\
\hline \multicolumn{8}{|l|}{ Lung function } \\
\hline $\mathrm{FEV}_{\mathrm{I}} / \mathrm{FVC}(\%)$ & $50.9 \pm 12.9$ & $54.8 \pm 10.9$ & $50.4 \pm 13.0$ & $<0.00 \mathrm{I}^{\#}$ & $56.5 \pm 1 \mathrm{I} .4$ & $50.6 \pm 12.9$ & $0.004^{\#}$ \\
\hline$\%$ predicted $\mathrm{FEV}_{1}$ & $56.7 \pm 21.1$ & $64.2 \pm 18.2$ & $56.0 \pm 21.2$ & $<0.00 \mathrm{I}^{\#}$ & $69.6 \pm 20.1$ & $56.2 \pm 21.0$ & $<0.00 \mathrm{I}^{\#}$ \\
\hline$\%$ predicted FVC & $87.5 \pm 20.8$ & $94.0 \pm 17.8$ & $86.8 \pm 21.0$ & $<0.00 I^{\#}$ & $98.8 \pm 16.1$ & $87.0 \pm 20.9$ & $<0.00 I^{\#}$ \\
\hline \multicolumn{8}{|l|}{ GOLD stage } \\
\hline 1 & $148(14.7)$ & $17(18.3)$ & $131(14.3)$ & \multirow{4}{*}{$<0.00 \mathrm{I}^{\ddagger}$} & $13(31.0)$ & $135(14.0)$ & \multirow{4}{*}{$<0.001^{\ddagger}$} \\
\hline II & $463(45.9)$ & $58(62.4)$ & $405(44.3)$ & & $22(52.4)$ & $44 \mid(45.7)$ & \\
\hline III & $285(28.3)$ & $15(16.1)$ & $270(29.5)$ & & $6(14.3)$ & $279(28.9)$ & \\
\hline IV & $112(11.1)$ & $3(3.2)$ & $109(11.9)$ & & I (2.4) & III (II.5) & \\
\hline \multicolumn{8}{|l|}{ Treatment for COPD or asthma } \\
\hline Any treatment & $988(98.0)$ & 91 (97.8) & $897(98.0)$ & $0.706 *$ & $42(100.0)$ & 946 (97.9) & $1.000 *$ \\
\hline SAMA & $10(1.0)$ & $\mathrm{I}(\mathrm{I} . \mathrm{I})$ & $9(1.0)$ & & $0(0.0)$ & $10(1.0)$ & \\
\hline SABA & $120(11.9)$ & $12(12.9)$ & $108(11.8)$ & & $5(11.9)$ & $115(11.9)$ & \\
\hline LAMA & $578(57.3)$ & $50(53.8)$ & $528(57.7)$ & & $22(52.4)$ & $556(57.6)$ & \\
\hline LABA & $140(13.9)$ & $6(6.5)$ & $134(14.6)$ & & $2(4.8)$ & $138(14.3)$ & \\
\hline LABA/LAMA & $199(19.7)$ & $10(10.8)$ & $189(20.7)$ & & $5(11.9)$ & $194(20.1)$ & \\
\hline ICS & $75(7.4)$ & $8(8.6)$ & $67(7.3)$ & & $3(7.1)$ & $72(7.5)$ & \\
\hline ICS/LABA & $404(40.1)$ & $64(68.8)$ & $340(37.2)$ & & $31(73.8)$ & $373(38.6)$ & \\
\hline Expectorant & $250(24.8)$ & $10(10.8)$ & $240(26.2)$ & & $6(14.3)$ & $244(25.3)$ & \\
\hline Xanthine derivatives & $166(16.5)$ & $13(14.0)$ & $153(16.7)$ & & $7(16.7)$ & $159(16.5)$ & \\
\hline Leukotriene receptor antagonist & $95(9.4)$ & $23(24.7)$ & $72(7.9)$ & & $12(28.6)$ & $83(8.6)$ & \\
\hline Anti-lgE antibody & $4(0.4)$ & $0(0.0)$ & $4(0.4)$ & & $0(0.0)$ & $4(0.4)$ & \\
\hline Systemic steroid (oral/injection) & $32(3.2)$ & $2(2.2)$ & $30(3.3)$ & & $2(4.8)$ & $30(3.1)$ & \\
\hline Oxygen therapy & $132(13.1)$ & $2(2.2)$ & $130(14.2)$ & & I (2.4) & $|3|(\mid 3.6)$ & \\
\hline Ventilatory support/surgical therapy & $5(0.5)$ & $0(0.0)$ & $5(0.5)$ & & $0(0.0)$ & $5(0.5)$ & \\
\hline Other & $66(6.5)$ & $5(5.4)$ & $61(6.7)$ & & $3(7.1)$ & $63(6.5)$ & \\
\hline
\end{tabular}

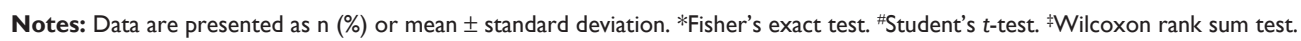

Abbreviations: ACOS, asthma-COPD overlap syndrome; BMI, body mass index; FEV , forced expiratory volume in I second; FVC, forced vital capacity; GOLD, Global Initiative for Chronic Obstructive Lung Disease; ICS, inhaled corticosteroid; IgE, immunoglobulin E; LABA, long-acting beta agonist; LAMA, long-acting muscarinic antagonist; SABA, short-acting beta agonist; SAMA, short-acting muscarinic antagonist. 


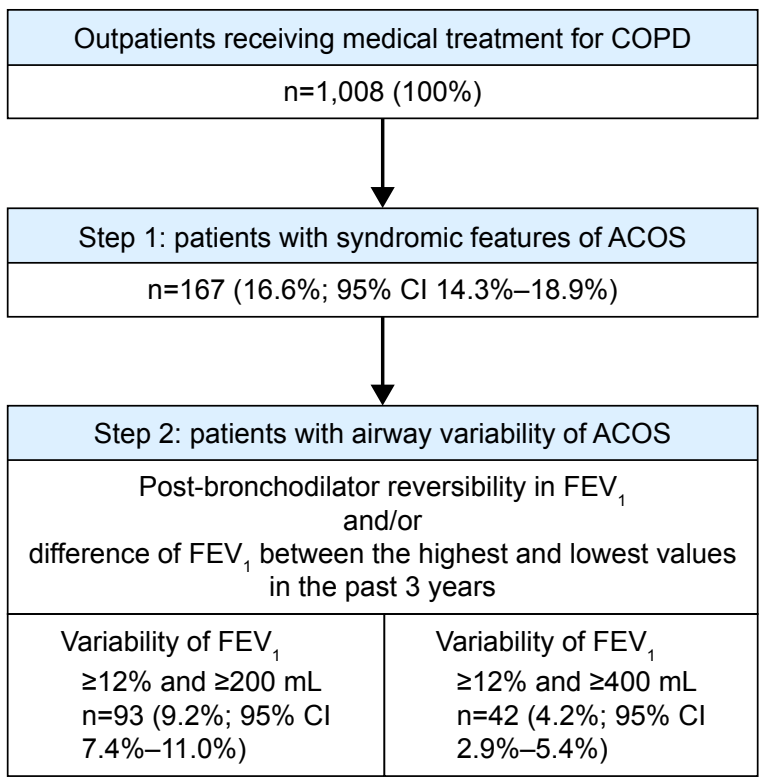

Figure I Identification of patients with ACOS using a stepwise approach. Abbreviations: ACOS, asthma-COPD overlap syndrome; $\mathrm{Cl}$, confidence interval; $\mathrm{FEV}_{1}$, forced expiratory volume in I second.

features favoring COPD). In the next step, 93 (9.2\%) patients who also had $\geq 12 \%$ and $\geq 200 \mathrm{~mL} \mathrm{FEV}_{1}$ variability were identified as having ACOS. According to the other criterion, $42(4.2 \%)$ patients who had $\geq 12 \%$ and $\geq 400 \mathrm{~mL} \mathrm{FEV}_{1}$ variability (in addition to the syndromic features of ACOS) were identified as having ACOS.

Of the total population, 595 patients $(59.0 \%$; 95\% CI $56.0 \%-62.1 \%$ ) had either syndromic or spirometric ( $\geq 12 \% / \geq 200 \mathrm{~mL} \mathrm{FEV}$, variability) features of ACOS or both. Similarly, 328 patients (32.5\%; 95\% CI 29.6\%-35.4\%) had either syndromic features or $\geq 12 \% / \geq 400 \mathrm{~mL}$ of $\mathrm{FEV}_{1}$ variability, or both.

\section{Characteristics of patients identified as having ACOS}

The demographic and clinical characteristics of ACOS patients, identified by the stepwise approach (who fulfilled the criteria for both the syndromic features and spirometry), were compared with those of patients with COPD alone (Table 2). ACOS patients were of significantly younger age, had greater body weight, shorter duration of COPD, and lower number of pack-years. Spirometry results showed that $\mathrm{FEV}_{1} / \mathrm{FVC}, \%$ predicted $\mathrm{FEV}_{1}$, and \% predicted FVC were significantly greater in ACOS patients than in COPDalone patients. The distribution of patients in each GOLD stage was also significantly different between the ACOS and the COPD-alone group; the ACOS group had fewer patients classified as severe.

The ratio of patients who received any medical treatment was not significantly different between the ACOS and COPDalone patients (Table 2). Inhaled corticosteroids (ICSs) were used by $7.1 \%-8.6 \%$ of ACOS patients and $7.3 \%-7.5 \%$ of COPD-alone patients. The ratio of patients who used an ICS/ long-acting $\beta_{2}$-agonist (LABA) combination was higher in the ACOS $(68.8 \%-73.8 \%)$ than in the COPD-alone group $(37.2 \%-38.6 \%)$, although these percentages were not compared by statistical tests.

Both the proportion of patients who experienced exacerbations and the number of exacerbations in the previous year were similar between ACOS patients and COPD-alone patients (Table 3). The proportion of patients with moderate/ severe exacerbations and the number of events were also similar between the groups.

Dyspnea symptoms, assessed by $\mathrm{mMRC}$, were significantly milder in ACOS patients than in COPD-alone patients (Table 4). Total and functional-state CCQ scores were significantly better in ACOS patients who were identified by the syndromic features and $\geq 12 \% / \geq 200 \mathrm{~mL} \mathrm{FEV}_{1}$ variability.

Regarding biomarkers of eosinophilic inflammation, both the absolute counts and the percentage of peripheral blood eosinophils were significantly greater in ACOS patients than in COPD-alone patients (Table 5). However, a statistically

Table 3 COPD exacerbations during the past year

\begin{tabular}{|c|c|c|c|c|c|c|c|c|c|}
\hline \multirow[t]{2}{*}{$\begin{array}{l}\text { COPD } \\
\text { exacerbation }\end{array}$} & \multirow[t]{2}{*}{$\begin{array}{l}\text { Total } \\
(n=I, 008)\end{array}$} & \multicolumn{4}{|c|}{$\begin{array}{l}\text { ACOS defined by syndromic features and } \\
\text { FEV, variability } \geq 12 \% \text { and } \geq 200 \mathrm{~mL}\end{array}$} & \multicolumn{4}{|c|}{$\begin{array}{l}\text { ACOS defined by syndromic features and } \\
\text { FEV, variability } \geq 12 \% \text { and } \geq 400 \mathrm{~mL}\end{array}$} \\
\hline & & $\begin{array}{l}\text { ACOS } \\
(n=93)\end{array}$ & $\begin{array}{l}\text { COPD alone } \\
(n=9 \mid 5)\end{array}$ & Ratio* & $P$-value & $\begin{array}{l}\text { ACOS } \\
(n=42)\end{array}$ & $\begin{array}{l}\text { COPD alone } \\
(n=966)\end{array}$ & Ratio* & P-value \\
\hline \multicolumn{10}{|l|}{ Any } \\
\hline No of patients (\%) & $284(28.2)$ & $25(26.9)$ & $259(28.3)$ & - & $0.810^{\#}$ & $12(28.6)$ & 272 (28.2) & - & $1.000^{\#}$ \\
\hline No of events (rate) & $502(0.498)$ & $53(0.570)$ & $449(0.491)$ & 1.161 & $0.502^{\ddagger}$ & $31(0.738)$ & 47I (0.488) & $1.5 \mid 4$ & $0.176^{\ddagger}$ \\
\hline \multicolumn{10}{|l|}{ Moderate or severe } \\
\hline No of patients (\%) & $265(26.3)$ & $24(25.8)$ & $24 \mid(26.3)$ & - & $1.000^{\#}$ & $12(28.6)$ & $253(26.2)$ & - & $0.722^{\#}$ \\
\hline No of events (rate) & $452(0.448)$ & $48(0.516)$ & $404(0.442)$ & 1.169 & $0.497^{\ddagger}$ & $29(0.690)$ & $423(0.438)$ & 1.577 & $0.147^{\ddagger}$ \\
\hline
\end{tabular}

Notes: *ACOS:COPD alone. "Fisher's exact test. \#Negative binomial regression analysis.

Abbreviations: ACOS, asthma-COPD overlap syndrome; $\mathrm{FEV}_{1}$, forced expiratory volume in I second; No, number. 
Table 4 Symptoms and health status

\begin{tabular}{|c|c|c|c|c|c|c|c|}
\hline \multirow[t]{2}{*}{ Item } & \multirow[t]{2}{*}{ Total } & \multicolumn{3}{|c|}{$\begin{array}{l}\text { ACOS defined by syndromic features and } \\
\text { FEV } \text {, variability } \geq 12 \% \text { and } \geq 200 \mathrm{~mL}\end{array}$} & \multicolumn{3}{|c|}{$\begin{array}{l}\text { ACOS defined by syndromic features and } \\
\text { FEV, variability } \geq 12 \% \text { and } \geq 400 \mathrm{~mL}\end{array}$} \\
\hline & & Acos & COPD alone & $P$-value* & Acos & COPD alone & $P$-value* \\
\hline \multirow[t]{2}{*}{ mMRC score } & $n=938$ & $n=90$ & $\mathrm{n}=848$ & & $n=40$ & $n=898$ & \\
\hline & $1.4 \pm 1 . I$ & $1.0 \pm 1.0$ & $1.5 \pm 1.2$ & $<0.001$ & $0.8 \pm 0.9$ & $1.5 \pm 1.1$ & $<0.001$ \\
\hline $\mathrm{CCQ}$ & $\mathrm{n}=938$ & $n=91$ & $n=847$ & & $n=41$ & $n=897$ & \\
\hline Symptoms & $1.8 \pm 1.1$ & $1.7 \pm 1.0$ & $1.8 \pm 1.1$ & 0.365 & $1.7 \pm 1.0$ & $1.8 \pm 1.1$ & 0.556 \\
\hline Functional state & $1.8 \pm 1.4$ & $1.3 \pm 1.2$ & $1.8 \pm 1.4$ & 0.002 & $1.4 \pm 1.2$ & $1.8 \pm 1.4$ & 0.066 \\
\hline Mental state & $1.5 \pm 1.5$ & $1.3 \pm 1.4$ & $1.5 \pm 1.5$ & 0.285 & $1.5 \pm 1.5$ & $1.5 \pm 1.5$ & 0.854 \\
\hline Total score & $1.7 \pm 1.1$ & $1.5 \pm 0.9$ & $1.7 \pm 1.1$ & 0.011 & $1.5 \pm 1.0$ & $1.7 \pm 1.1$ & 0.279 \\
\hline
\end{tabular}

Notes: Data are presented as mean \pm standard deviation. *Student's $t$-test.

Abbreviations: ACOS, asthma-COPD overlap syndrome; CCQ, Clinical COPD Questionnaire; FEV , forced expiratory volume in I second; mMRC, modified British Medical Research Council.

significant difference in FeNO concentrations between the ACOS and COPD-alone groups was not found (Table 5).

\section{Discussion}

This study identified ACOS patients among outpatients who were receiving treatment for COPD in real-life clinical settings using the stepwise approach, including both syndromic features and reversible airway variability, as stated in the GINA/GOLD report. ${ }^{1}$

Among patients who were receiving medical treatment for COPD, $9.2 \%$ and $4.2 \%$ had the syndromic features of ACOS, and $\geq 12 \% / \geq 200 \mathrm{~mL} \mathrm{FEV}_{1}$ variability and $\geq 12 \% / \geq 400 \mathrm{~mL}$ $\mathrm{FEV}_{1}$ variability, respectively. These proportions reflect the real-world patients receiving medical treatment for COPD because this study consecutively enrolled eligible patients at each study site to minimize potential selection bias.

In previous reports, compared with patients with COPD alone, patients with ACOS had more frequent exacerbations, ${ }^{8-12}$ lower lung function, ${ }^{11,13}$ more severe symptoms, ${ }^{9,11,12}$ and lower health-related quality of life. ${ }^{9-11}$ In contrast, in this study, ACOS patients had less severe airflow limitation, milder dyspnea symptoms, and better functional status than the
COPD-alone patients. Moreover, the frequency of exacerbations was similar in both groups. This may be explained by the differences between patients' characteristics in the ACOS and COPD groups in our study; that is, the ACOS patients in this study were of younger age, had higher body weight, lower number of pack-years, and shorter disease duration than the COPD-alone patients. In addition, the proportion of patients prescribed ICS/LABA was higher in the ACOS group.

Blood eosinophil values were higher in the ACOS patients than in the COPD-alone patients, indicating that eosinophilic inflammation is increased in patients with ACOS. This is consistent with a recent report in which higher concentrations of blood eosinophils were observed in ACOS patients. ${ }^{14}$ We could not find any significant difference in FeNO measurements between the groups, although the usefulness of FeNO in differentiating ACOS, asthma, and COPD was suggested in other studies. ${ }^{14-16}$ This was probably due to the relatively smaller number of patients with FeNO measurements, which limited statistical power. Because testing procedures for blood eosinophils and FeNO are minimally invasive for patients, these biomarkers may be promising tools for diagnosis of ACOS in clinical practice.

Table 5 Inflammatory biomarkers

\begin{tabular}{|c|c|c|c|c|c|c|c|}
\hline \multirow[t]{2}{*}{ Biomarker } & \multirow[t]{2}{*}{ Total } & \multicolumn{3}{|c|}{$\begin{array}{l}\text { ACOS defined by syndromic features } \\
\text { and } F E V \text {, variability } \geq 12 \% \text { and } \geq 200 \mathrm{~mL}\end{array}$} & \multicolumn{3}{|c|}{$\begin{array}{l}\text { ACOS defined by syndromic features } \\
\text { and } F E V_{1} \text { variability } \geq I 2 \% \text { and } \geq 400 \mathrm{~mL}\end{array}$} \\
\hline & & ACOS & COPD alone & $P$-value* & ACOS & COPD alone & $P$-value* \\
\hline Peripheral blood & $\mathrm{n}=854$ & $n=78$ & $n=776$ & & $n=37$ & $\mathrm{n}=817$ & \\
\hline eosinophil count (cells/ $\mu \mathrm{L}$ ) & $239.1 \pm 234.6$ & $368.3 \pm 362.8$ & $226.1 \pm 213.6$ & 0.001 & $450.4 \pm 448.6$ & $229.5 \pm 215.7$ & 0.005 \\
\hline Peripheral blood & $\mathrm{n}=854$ & $\mathrm{n}=78$ & $\mathrm{n}=776$ & & $n=37$ & $\mathrm{n}=817$ & \\
\hline eosinophil rate (\%) & $3.6 \pm 3.2$ & $5.3 \pm 4.6$ & $3.5 \pm 3.0$ & $<0.001$ & $6.7 \pm 5.5$ & $3.5 \pm 3.0$ & 0.001 \\
\hline \multirow[t]{2}{*}{$\mathrm{FeNO}(\mathrm{ppb})$} & $\mathrm{n}=224$ & $\mathrm{n}=36$ & $n=188$ & & $n=19$ & $\mathrm{n}=205$ & \\
\hline & $27.5 \pm 21.2$ & $33.1 \pm 17.5$ & $26.4 \pm 21.7$ & 0.080 & $33.7 \pm 15.3$ & $26.9 \pm 21.6$ & 0.182 \\
\hline
\end{tabular}

Notes: Data are presented as mean \pm standard deviation. *Student's $t$-test.

Abbreviations: ACOS, asthma-COPD overlap syndrome; FeNO, fractional exhaled nitric oxide; $\mathrm{FEV}_{\text {, }}$, forced expiratory volume in I second. 
Airway reversibility testing is not commonly performed in clinical practice compared with spirometry. In fact, data from airway reversibility testing were available for only 452 of 1,008 patients in our population, although this study also adopted long-term airway variability, that is, the maximum difference in $\mathrm{FEV}_{1}$ within 3 years, to evaluate variable airflow limitation. The diagnostic differentiation between asthma and COPD cannot be clearly made by simply using the results of reversibility of airway obstruction induced by a BD. In addition to airway variability, syndrome-based assessment is important to identify patients with ACOS as stated in the GINA/GOLD report.

This study included only patients who had been diagnosed and were receiving medical treatment for COPD for $>1$ year. Therefore, the results obtained here cannot be directly extrapolated to a population of undiagnosed patients with respiratory symptoms, with the assumption that starting treatment may mask the syndromic features of ACOS. Another prospective study is required to reveal the prevalence of ACOS among patients with newly diagnosed COPD. In addition, the difference in responses to ICSs between patients with and without underlying eosinophilic inflammation was not investigated in this study. Thus, it would be of interest to evaluate such differences in a future study and also examine possible similarities in pathogenic and clinical characteristics between smokers with COPD and individuals with asthma.

\section{Conclusion}

In a cohort of patients who had been diagnosed and treated for COPD in a real-life clinical setting, we identified patients who had variable airflow limitation and both syndromic features of asthma and features of COPD. The proportions of patients identified as having ACOS based on the stepwise approach stated in the GINA/GOLD report were $9.2 \%$ and $4.2 \%$, depending on the $\mathrm{FEV}_{1}$ variability cutoff used. Compared with patients with COPD alone, patients identified as having ACOS had a similar rate of exacerbations but better lung function. Moreover, ACOS patients had significantly higher blood eosinophil values than patients with COPD alone, suggesting more pronounced eosinophilic airway inflammation in patients with ACOS.

\section{Acknowledgments}

The authors thank Nila Bhana, MSc, and Nicholas Smith, $\mathrm{PhD}$, from Edanz Group Japan K.K. for providing medical writing services, which were funded by AstraZeneca K.K. This study was sponsored by AstraZeneca K.K.

\section{Disclosure}

Hiromasa Inoue has received research funding and lecture fees from AstraZeneca K.K. Satoshi Morita has received personal fees from AstraZeneca K.K. Atsushi Yoshida and Tatsunori Jinnai are employees of AstraZeneca K.K. Masakazu Ichinose has received research funding from AstraZeneca K.K. The authors report no other conflicts of interest in this work.

\section{References}

1. Global Initiative for Asthma and Global Initiative for Chronic Obstructive Lung Disease. Diagnosis of diseases of chronic airflow limitation: asthma, COPD, and asthma-COPD overlap syndrome (ACOS). Available from: http://goldcopd.org/asthma-copd-asthmacopd-overlap-syndrome/. Accessed July 6, 2016.

2. Gibson PG, McDonald VM. Asthma-COPD overlap 2015: now we are six. Thorax. 2015;70(7):683-691.

3. Wurst KE, Kelly-Reif K, Bushnell GA, Pascoe S, Barnes N. Understanding asthma-chronic obstructive pulmonary disease overlap syndrome. Respir Med. 2016;110:1-11.

4. van der Molen T, Willemse BW, Schokker S, ten Hacken NH, Postma DS, Juniper EF. Development, validity and responsiveness of the Clinical COPD Questionnaire. Health Qual Life Outcomes. 2003;1(1):13.

5. Global Initiative for Chronic Obstructive Lung Disease (GOLD) Global strategy for the diagnosis, management, and prevention of chronic obstructive pulmonary disease 2017 report. Available from: http://goldcopd.org/gold-2017-global-strategy-diagnosis-managementprevention-copd/. Accessed January 13, 2017.

6. Kostikas K, Clemens A, Patalano F. The asthma-COPD overlap syndrome: do we really need another syndrome in the already complex matrix of airway disease? Int J Chron Obstruct Pulmon Dis. 2016; 11:1297-1306.

7. Cazzola M, Rogliani P. Do we really need asthma-chronic obstructive pulmonary disease overlap syndrome? J Allergy Clin Immunol. 2016; 138(4):977-983.

8. Hardin M, Silverman EK, Barr RG, et al. The clinical features of the overlap between COPD and asthma. Respir Res. 2011;12:127.

9. Miravitlles M, Soriano JB, Ancochea J, et al. Characterisation of the overlap COPD-asthma phenotype. Focus on physical activity and health status. Respir Med. 2013;107(7):1053-1060.

10. Hardin M, Cho M, McDonald ML, et al. The clinical and genetic features of COPD-asthma overlap syndrome. Eur Respir J. 2014; 44(2):341-350.

11. Menezes AM, Montes de Oca M, Pérez-Padilla R, et al. Increased risk of exacerbation and hospitalization in subjects with an overlap phenotype: COPD-asthma. Chest. 2014;145(2):297-304.

12. Nielsen M, Barnes CB, Ulrik CS. Clinical characteristics of the asthmaCOPD overlap syndrome - a systematic review. Int J Chron Obstruct Pulmon Dis. 2015;10:1443-1454.

13. Kim MA, Noh CS, Chang YJ, et al. Asthma and COPD overlap syndrome is associated with increased risk of hospitalisation. Int J Tuberc Lung Dis. 2015;19(7):864-869.

14. Kobayashi S, Hanagama M, Yamanda S, Ishida M, Yanai M. Inflammatory biomarkers in asthma-COPD overlap syndrome. Int J Chron Obstruct Pulmon Dis. 2016;11:2117-2123.

15. Tamada T, Sugiura H, Takahashi T, et al. Biomarker-based detection of asthma-COPD overlap syndrome in COPD populations. Int J Chron Obstruct Pulmon Dis. 2015;10:2169-2176.

16. Karampitsakos T, Gourgoulianis KI. Asthma-COPD Overlap Syndrome (ACOS): single disease entity or not? Could exhaled nitric oxide be a useful biomarker for the differentiation of ACOS, asthma and COPD? Med Hypotheses. 2016;91:20-23. 


\section{Publish your work in this journal}

The International Journal of COPD is an international, peer-reviewed journal of therapeutics and pharmacology focusing on concise rapid reporting of clinical studies and reviews in COPD. Special focus is given to the pathophysiological processes underlying the disease, intervention programs, patient focused education, and self management protocols.

This journal is indexed on PubMed Central, MedLine and CAS. The manuscript management system is completely online and includes a very quick and fair peer-review system, which is all easy to use. Visit http://www.dovepress.com/testimonials.php to read real quotes from published authors. 